\title{
CORRIGENDUM
}

\section{Influence of Bax or Bcl-2 overexpression on the ceramide-dependent apoptosis pathway in glioma cells}

M Sawada, S Nakashima, Y Banno, H Yamakura, K Takenaka, J Shinoda, Y Nishimura, N Sakai and Y Nozawa

Oncogene (2006) 25, 7440. doi:10.1038/sj.onc.1210105

Correction to: Oncogene (2000) 19, 3508-3520.

A mistake occurred during the preparation of this manuscript, such that the top panels from Figure 10b and $\mathrm{c}$ used data that had been previously published in Cell Death and Differentiation. These data are similar in appearance, but was performed without the transfected neomycin-resistant expression vector. The correct data are published here.

The authors would like to apologize for this error.

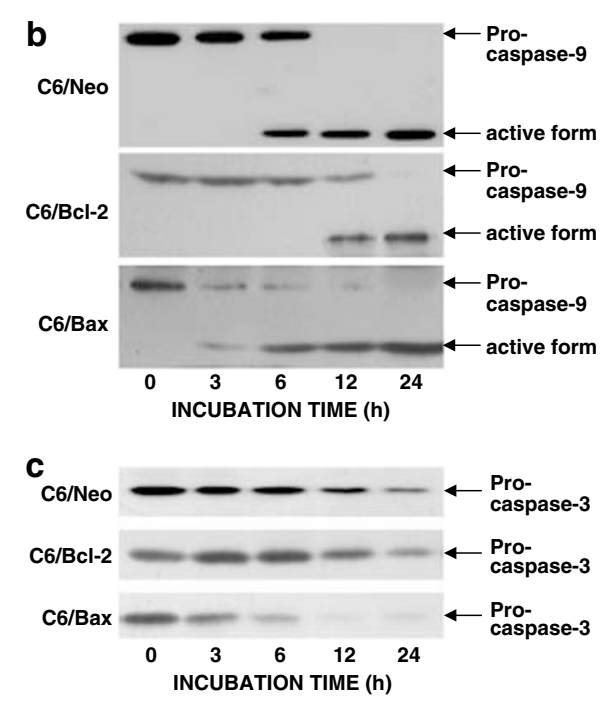

